\title{
Suburban wildlife: Lessons, challenges, and opportunities
}

\author{
STEPHEN DISTEFANO* \\ sdestef@ forwild.umass.edu \\ USCS Massachusetts Comperative Fish and Wildlife Research Unit. Holdsworth Nantul Resources Center. \\ University of Massachusetts. Amherst, MA 01003, USA
}

\section{ROBERT D. DEBLINGER}

Massachisetts Division of Fisheries and Wildife, Field Headquarters, I Rabhit Hill Road, Westborough. MA 01581. USA

CRAIG MILLER

School of Renewable Natural Resources, Renewable Natural Resource Building, Lonisiana State University. Balon Rouge, LA 70803, USA

\begin{abstract}
The United States, as well as most developed and many developing nations worldwide, is becoming increasingly urban and suburban. Although urban, suburban, and commercial development account for less than one percent to just over $20 \%$ of land use among states. $50-90 \%$ of the residents of those states can be classified as urban or suburban dwellers. The population of the U.S. as a whole has risen from being $>95 \%$ rural in the $1790 \mathrm{~s}$ to about $80 \%$ urban-suburban today. With these changes in land use and demographic patterns come changes in values and attitudes; many urbanites and suburbanites view wildlife and nature differently than rural residents. These are among the challenges faced by wildlife biologists and natural resource managers in a rapidly urbanizing world. In 2003, we convened a symposium to discuss issues related to suburban wildlife. The papers presented in this special issue of Urban Ecosystems address the lessons learned from the early and recently rapidly expanding litcrature, the challenges we face today, and the opportunities that can help deal with what is one of the biggest challenges to conservation in a modernizing world.
\end{abstract}

Keywords: demography, land use patterns, suburban wildlife, urban wildlife

\section{Introduction}

The United States, as well as most developed and many developing nations, is becoming increasingly urban and suburban and less rural in both the characteristics of its human population and in its land use patterns (Vitousek et al., 1997; Cohen, 2003; Auch et al., 2004). With these changes in demography and landscape come changes in philosophies and attitudes; suburban residents often view land and wildlife in a different light than rural inhabitants (Deblinger et al., 1999). These changes in land use patterns, human demographic characteristics, and philosophies and attitudes present a challenge to ecologists, who strive to understand the relationships of the natural world, and natural resource managers, who attempt to balance the needs of people and wildlife.

*Author to whom all correspondence should be addressed. 
In the fall of 2003, we organized a symposium on suburban wildlife for the $10^{\text {th }}$ annual conference of The Wildlife Society, the international organization of professional wildlife biologists, to discuss these concerns in light of what we see as major issues for the conservation and management of natural resources. We structured the symposium around three broad themes relative to the evolution of issues for wildlife and people in suburbia: lessons, challenges, and opportunities. We invited speakers who have had experience in the realm of suburban wildlile and human dimensions of wildlife to make research and conceptual presentations, and to follow their talks with manuscripts for possible inclusion in this special issue of Urban Ecoystems.

Our focus was on suburban, rather than urban, landscapes for several reasons (although there is often broad overlap between the two). First, the arcas experiencing the greatest rates of development, and hence the highest loss of open space, are along the urban-rural fringe, in areas just beyond or within ever-increasing commuting distances from the urban edge, and further into the rural countryside (Heimlich and Anderson, 2001). The type of development (single-family homes with the support services [roads, power, water, sewerage] that go along with them) qualifies these areas as suburban landscapes. Secondly, the mix of suburban neighborhoods and the built environment with remnant wildlile habitats such as woodlots and abandoned fields, newly created habitats such as parks and landscaped backyards, and resources such as food and cover, attract or retain many wildlife species, creating a high encounter rate between humans and wildlife. Thirdly, these high rates of human-wildlife encounters often lead to high rates of human-wildlife conflicts; such conflicts demand large amounts of attention, time, and resources from local natural resource management agencies.

In this paper, we examine some of the trends in human population and land use in the U.S. that show society to be increasingly suburban. Our paper also serves as an introduction to the topic of suburban wildlife, and we provide a description and explanation of the symposium and this special issue of Urban Ecosystems, which draw their structure from the single-word themes of Lessons, Challenges, and Opportunities. Finally, we provide a backdrop for exploring the relatively recent increase in interest in urban and suburban ecology, wildlite, and human dimensions, and the emergence of these issues as major topics in ecology, wildlife science, and natural resource management.

\section{Lessons}

Lessons in the topic of urban and suburban wildlife come from a variety of sources, the first of which is literature that dates back to at least the early part of the 1900s, where pioneering researchers first published their ideas on wildlife living in close proximity to humans (see DeStefano and DeGraaf, 2003). Much of this early literature was focused on songbirds, and most of it emphasized the positive aspects of wildlife. During the 1960s and 1970s, however, several symposia were held to address issues and growing interest in urban and suburban wildlife (e.g., Noyes and Progulske, 1974; Euler, 1975; Kirkpatrick, 1978). Much of this information is available in published proceedings, and as such was not as intensely scrutinized or as readily available as peer-reviewed literature. Nonetheless, these proceedings are valuable documents for their insights, ground-breaking ideas, and early research. In the last two decades interest in urban ecology has been growing at a tremendous 
rate, as evidenced by the numbers of scientific publications on all topics of urban and suburban ecology (Adams, this volume). Synthesis documents are also beginning to appear (e.g., Marzluff et al., 2001), adding greatly to the knowledge base of suburban wildlife and management. And importantly, information from the practical, on-the-ground experiences of wildlife managers is also becoming available (Decker et al., 2004). Thus, lessons abound in the foundation literature from symposium proceedings and early published papers, from the rapidly growing recent scientific literature, and from the numerous experiences of every wildlife and resource management agency in the country who deal with these issues on a daily basis.

\section{Challenges}

The biggest challenge to conservation is the growing human population. As the global human population continues to increase exponentially, a higher proportion of people become urban and rural residents, with fewer people living a rural lifestyle. In the U.S., the Bureau of the Census (BOC) (www.census.gov) defines urban areas as those areas with at least 500-1,000 people per $\mathrm{mi}^{2}$ (193-386 people per $\mathrm{km}^{2}$ ); this includes metropolitan areas and suburbs. Rural areas would be those areas with $<500$ people per $\mathrm{mi}^{2}$ ( $<193$ people per $\mathrm{km}^{2}$ ). According to BOC data, $<5 \%$ of the nation's population was considered urban in 1790 ; today about $80 \%$ of U.S. citizens live in cities and towns, with only $15 \%$ living in rural communities (figure 1). The proportion of U.S. residents who can be classified as urban versus rural has thus increased to the point where the population is overwhelmingly urban. The same is true for the rest of the world: only about $2 \%$ of people lived in cities in 1800 ; today about half the world's population lives in cities, and this is growing (Cohen, 2003). With this increasing urbanization of humans, cities are reaching extraordinary sizes. In 1900 there were no cities with 10 million people. New York City passed this mark in 1950. By 2000 , 19 cities throughout the world had 10 million people or more, but only four of theseTokyo, Osaka, New York, and Los Angeles-were in industrialized nations (Cohen, 2003). As cities get bigger, they expand outward, claiming more space and requiring additional resources for their continued existence. The issue of accelerated resource consumption goes hand-in-hand with the rapidly increasing human population, especially in developed nations.

Land use patterns in the U.S. are another critical issue. To examine the proportion of urban and suburban development by state, we derived land cover statistics from the National Land Cover Database (NLCD) (http://landcover.usgs.gov/nlcd.asp). For each state, we summed the land coverage for low intensity residential (NLCD category 21 ), high intensity residential (22), commercial-industrial-transportation (23), and urban-recreational grasses (85), and divided by the state's total land area to arrive at a percentage of urban-suburban land use. All other categories (e.g., forests, agriculture, wetlands, open water) made up the remaining proportion of each state as nonurban-nonsuburban land cover. We then categorized each state as $<1 \%, 1-5 \%, 6-10 \%$, and $>20 \%$ urban-suburban (there were no states with $11-$ $19 \%$ urban-suburban land cover). Many western states have $<1 \%$ of their lands in urban, suburban, or commercial development (figure 2). California, Washington, and the states throughout the Midwest and southeast have $<5 \%$ of this kind of development. The Northeast 


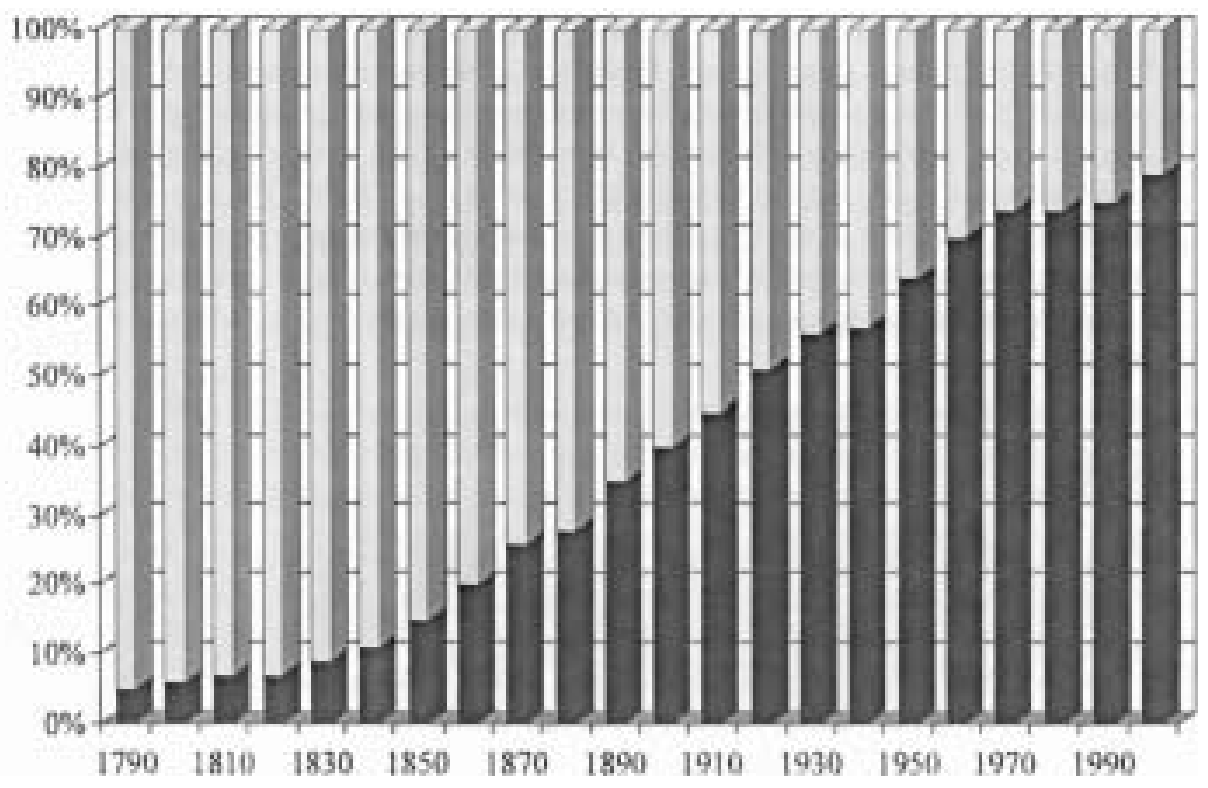

Figure 1. Proportion of U.S. residents classified as rural (light-colored portion) versus urban (dark-colored portion) dwellers from 1790 to 2000. The U.S. Bureau of Census classifies urban-suburban regions as areas with $>193$ people per $\mathrm{km}^{2}$ ( $>50$ people per $\mathrm{mi}^{2}$ ). Urban-suburban residents have increased from about $5 \%$ in 1790 10 about $80 \%$ by 2000 . (Data derived from U.S. Bureau of Census.)
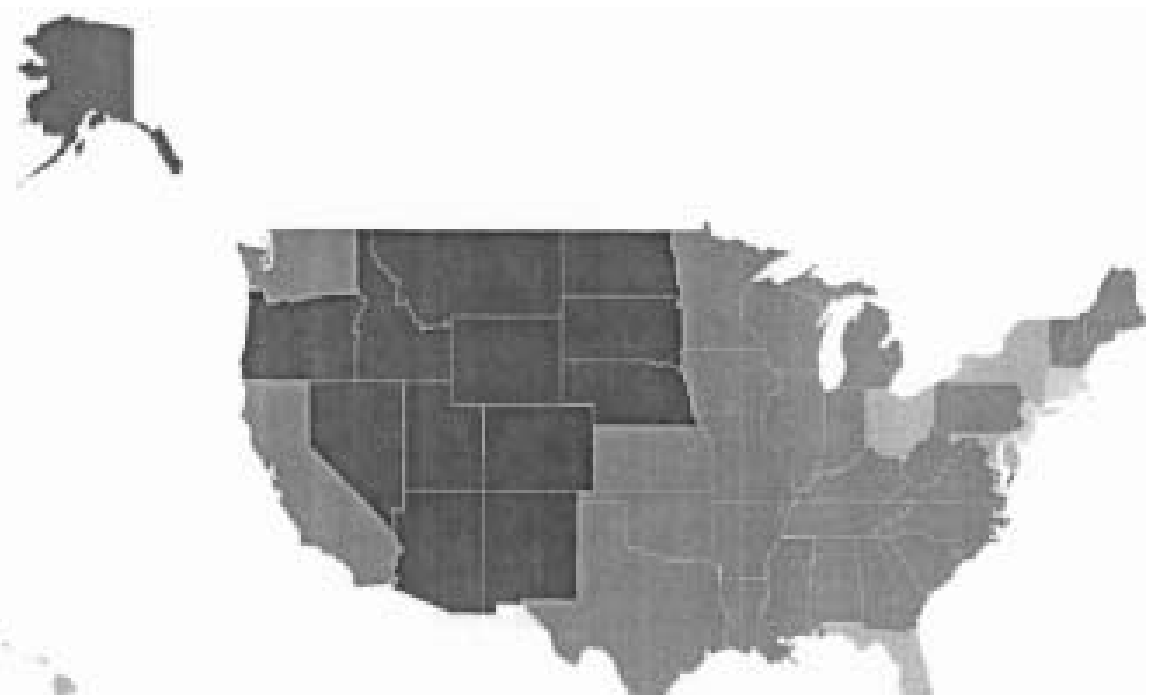

Figure 2. Proportion of urban-suburban-commercial development by state: light gray are states with $>20 \%$ of their land base in development: medium gray is .5-10\%; dark gray is $1-5 \%$, and black is < $1 \%$. (Data derived from the U.S. Geological Survey, National Land Cover Database.) 

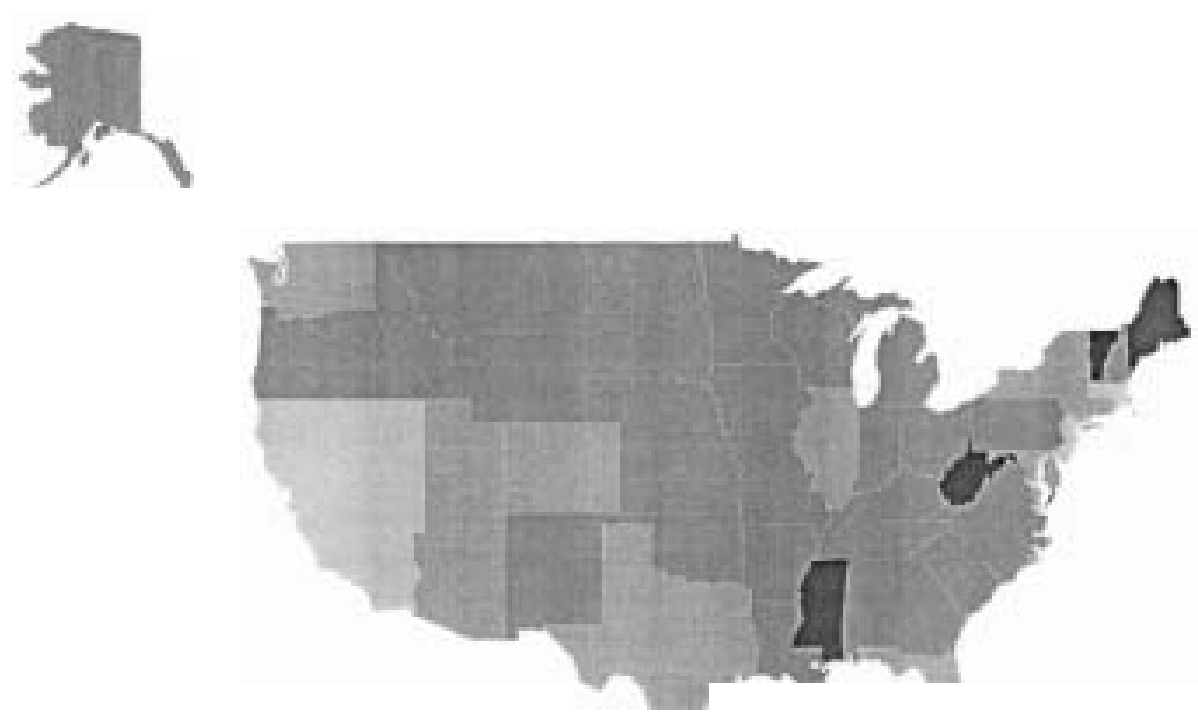

Figure 3. Proportion of urban-suburban residents (versus rural residents) by state: light gray are states with $>90 \%$ urban-suburban residents: medium gray is $81-90 \%$; dark gray is $51-80 \%$, and black is $<50 \%$. (Data derived from the U.S. Geological Survey, National Land Cover Database.)

is the only region of the country with some states with significant proportions of their land base in urban-suburban development. Most states in this region are in the 6-10\% range, while four states-Massachusetts, Connecticut, Rhode Island, and New Jersey-have just over $20 \%$ of their land base in urban and suburban development.

The proportion of residents of each state that can be classified as urban or suburban dwellers gives a different picture to the country, however. We used BOC data 10 determine the proportion of urban-suburban to rural residents for each state. The percentage of urbansuburban dwellers is high, $>50 \%$ for all but 4 states, and, surprisingly, those 4 states are east of the Mississippi River (Mississippi, West Virginia, Maine, and Vermont) (figure 3). States like California, Massachusetts, Rhode Island, New Jersey, and even Nevada have $>90 \%$ of their population as urban/suburban dwellers. These demographic patterns represent significant challenges and have important implications to conservation and wildlife management. In addition to where people live, it is how we live that is helping to redefine our socicty as largely suburban: $66 \%$ of U.S. residents live in single-unit housing and $76 \%$ drive to work alone, averaging about half an hour of travel time (U.S. Burcau of Census, http://www.census.gov).

The preponderance of the U.S. Iand base not currently under urban, suburban, or commercial development has lead some pro-development groups to question programs or approaches to planned development and other attempts to limit sprawl. However, land use is only one concern. The huge increase in resource use that goes along with urbanization trends is also an important issue for the preservation of natural areas and the conservation of 
natural communities. The concept of a growing ecological footprint (Sanderson et al., 2002) of metropolitan centers and their surrounding suburbs is a critical element in the suite of challenges facing resource managers.

\section{Opportunities}

With challenges come opportunities. As is often the case with issues of conservation, it is a sense of urgency that creates the motivation for action. Suburban development and loss of open space are occurring at unprecedented rates in the U.S. and much of the world. The issue is well known to most citizens, from first-hand experience as well as from the popular literature and media.

Current technology allows biologists to reach people as never before. A more aware and interested public creates increased educational opportunities. In addition, the recognition of the importance of human dimensions in the conservation of natural resources has reached new heights, and collaborations between ecologists and sociologists are growing. Stakeholder (Carpenter et al., 2000) involvement at local levels, more inventive and innovative approaches to conservation planning, such as the large-scale holistic Sonoran Desert Conservation Plan (http://www.pima.gov/sdcp/), and regional collaborative approaches to specific issues, such as animal damage and control (Curtis et al., this volume), are just some of the ways that ecologists, conservationists, and resource managers can, and must, face the challenges presented in the growing human landscape.

The issue of urban and suburban sprawl is widespread and ubiquitous throughout much of the world. It is arguably among the most important resource and conservation issues of the 21 st century. We hope that the ideas presented in this special issue of Urban Ecosystems contribute in a small way to this very large challenge.

\section{Acknowledgments}

We thank J. Hadidian, R. Brooks, and J. McDonald for helping us organize the symposium, the speakers and authors for participating, and the Urban Wildlife Working Group of The Wildlife Society for sponsoring our symposium. G. Guntenspergen and C. Knight were instrumental in the development of this special issue. C. Henner and K. Koenen provided insights and comments on an earlier draft of this paper. Funding and logistic support for some of the work represented here were provided in part by the U.S. Geological Survey's Cooperative Research Units Program, the Massachusetts Division of Fisheries and Wildlife, the Massachusetts Agricultural Experiment Station, University of Massachusetts-Amherst, the Berryman Institute East, and the Northeast Wildlife Damage Management Research and Outreach Cooperative.

\section{References}

Adams, L.W. (this volume) Urban wildlife ecology and management: A bricf history of the discipline. Urban Ecosvstems. 
Auch, R.. Taylor, J. and Acevedo, W. (2004) Urban growth in American cities: Glimpses of U.S. Urbanization. U.S. Dep. of the Interior, U.S. Geological Survey, Circular 1252, Reston, Virginia.

Carpenter, L.H., Decker. D.J. and Lipscomb. J.F. (2000) Stakeholder acceptance capacity in wildlife management. Hum. Dim. Wildl. 5, 5-19.

Curtis. P.D. San Julian. G.J. and Mattfeld, G.F. (this volume). A model of collaborative programming to address wildlife issues: The Northeast Wildlife Damage Management Research and Outreach Cooperative. Urban Ecosustems.

Cohen, J.E. (2003) Human population: The next half century. Science 302. 1172-1175.

Deblinger. R.D., Woytek, W.A. and Zwick, R.R. (1999) Demographics of voting on the 1996 Massachusetts ballot referendum. Himn. Dim. Wildl. 4. 40-55.

Decker. D.J.. Raik, D.B. and Sicmer, W.F. (2004) Commumity-based deer manasement, a practitioners' guide. Human Dimensions Resear. Unit, Cornell Univ., Ithaca. New York.

DeStefano. S. and DeGraaf, R.M. (2003) Exploring the ecology of suburban wildlife. Fromiers in Ecol. and the Envirm. 1,95-101.

Fuler. D. (ed.) (1975) Wildlife in Urban Canada. Symp. Proc.. Univ. Guelph and Ont. Ministry of Nat. Resour., Guclph, Ontario, Canada.

Heinlich, R.E. and Anderson, W.D. (2001) Developmem at the urban fringe and beymd. U.S. Dep. Agricul., Agricul. Econ. Rep. No. 803, Washington, D.C..

Kirkpatrick. C.M. (ed.) (1978) Wildlife and people. Symposium Proceedings, Dep. For. and Nat. Resour. and Ind. Coop. Exten. Serv., Purdue Univ.. West Lafayette. IN.

Marzluff, J.M.. Bowman, R. and Donnelly, R. (eds.) (2001) Avian Ecology and Comsenution in an Urbanizing World. Kluwer Acadenic Publ. Boston. Mass.

Noyes, J.H. and Progulske. D.R, (eds.) (1974) Wildlife in an Urbamizing Emiromment. Symp. Proc.. Coop. Exten. Serv. Univ. Mass., Amherst, Mass.

Sanderson, E.W., Jaiteh, M., Levy, M.A., Redford. K.H.. Wannebo, A.V. and Woolmer, G. (2002) The human footprint and the last of the wild. Bioscience 52, 891-904.

Vitousek. P.M.. Mooney. H.A., Lubchenco, J. and Melillo. J.M. (1997) Human domination of Earth's ecosystems. Science 277. 494-499. 